\title{
Effect of Pollarding for Fodder on Fine Root Dynamics of Soil Conservation Willow Trees in New Zealand
}

\author{
Ian R Mclvor ${ }^{*}$, Duncan Hedderley and Karen Mason \\ The New Zealand Institute for Plant \& Food Research Limited, Palmerston North, New Zealand
}

\begin{abstract}
A field study of the effect of pollarding on fine root development of tree willow (Salix matsudana $x$ alba 'Tangoio') was carried out measuring fine and coarse root length and mass for unpollarded (UP), pollarded (IP) and repollarded trees (RP) at 3-monthly intervals over a period of 1 year following pollarding. The IP trees had been pollarded once only, 3 years before the study began. The RP trees had been pollarded twice, 3 years before the study and at the commencement of the study. Soil cores (200 mm diameter) were taken at $150 \mathrm{~mm}$ depth intervals down to $600 \mathrm{~mm}$ at three angles and at two distances $(2 \mathrm{~m}$ and $3 \mathrm{~m})$ from the trunk. Willow tree roots were extracted from each soil core and fine $(<2 \mathrm{~mm}$ diameter) and coarse ( $\geq 2 \mathrm{~mm}$ diameter) root length and mass densities determined. Three trees were sampled for each treatment. Seasonal changes in fine root length density ( $f R L D$ ) of the UP trees were treated as a baseline, and differences due to pollarding, and the immediate effect of pollarding on fRLD were determined. Percentage of fRLD located in the upper $300 \mathrm{~mm}$ varied between $71 \%$ and $85 \%$ for IP and UP trees. Fine RLD of RP trees was $63 \%$ of that of IP trees 90 days after pollarding. Pollarding of the trees reduced fRLD in the $0-300 \mathrm{~mm}$ soil depth with little fRLD change at the 300$600 \mathrm{~mm}$ depth. One year following pollarding, mean fRLD of RP trees was $57 \%$ that of UP trees. Three years following pollarding (IP trees), mean fRLD was $77 \%$ of UP fRLD and 4 years after pollarding there was no significant difference in fRLD for pollarded (IP) trees within $3 \mathrm{~m}$ of the trunk, compared with the unpollarded treatment. The greatest reduction in fRLD following pollarding was for fine roots with diameter $0<1 \mathrm{~mm}$. The study suggested that the reduction in fine root density following repeat pollarding of mature Salix matsudana $\times$ alba 'Tangoio' willows at intervals less than 4 years may compromise their long-term effectiveness in binding soil and reducing erosion. Further research is needed to confirm this hypothesis.
\end{abstract}

\section{Keywords}

Willow, Pollarding, Soil stabilisation, Fine root, Slope

\section{Key Message}

The reduction in fine root density following repeat pollarding for fodder or size management of mature Salix matsudana $\times$ alba 'Tangoio' willows at intervals less than 4 years may compromise their long-term effectiveness in binding soil and reducing erosion.

\section{Introduction}

\section{New-Zealand is well known for its pastoral farm- ing}

Erosion is a significant environmental issue facing agricultural and forestry land uses in large parts of the hill country of New Zealand [1]. Forested hill country in the North Island, particularly, was cleared for pastoral farming by European settlers between 70 and 170 years ago. Following deforestation, pastoral hill country erosion became so severe, the Water and Soil Conservation Act was passed by the New Zealand Government in 1941. Affordable treebased erosion control measures for pastoral hill country were required to be established in the presence of grazing animals [1]. The two most suitable species proved to be poplar (Populus spp.) and willow (Salix spp.) [2]. Both spe- cies are readily established from large poles in the presence of stock, with a minimum of protection, are cheap to produce, and are easily transported and planted on steep unstable hill country [2]. Immediate reductions in pasture production follow landslide erosion events on steep hill country [3] and mature poplar and willow trees reduce the incidence of soil slippage to very low levels when compared

*Corresponding author: Ian R Mclvor, The New Zealand Institute for Plant \& Food Research Limited, Private Bag 11600, Palmerston North, New Zealand

Accepted: January 18, 2020

Published online: January 20, 2020

Citation: Mclvor IR, Hedderley D, Mason K (2020) Effect of Pollarding for Fodder on Fine Root Dynamics of Soil Conservation Willow Trees in New Zealand. Adv Environ Stud 4(1):252-260 
with slippage on nearby pasture control sites [4]. Pasture grasses alone are not sufficiently effective in reducing soil erosion following heavy or prolonged rain events [4], hence the emphasis in New Zealand on using Populus spp and Salix spp. to stabilise the soil and reduce slope erosion. The increased effectiveness of tree-pasture systems over pasture alone in reducing slope erosion is thought to be contributed by several factors including their superior root tensile strength, the extensive nature of their root systems, their ability to extend their root system into the underlying rock, and their ability to de-water the slope during the growing season $[2,5]$. However, mature willows are vulnerable to branch breakage or toppling in wet or windy conditions, can damage farm infrastructure (e.g. blocking sheep tracks and roadways, breaking fences) and are costly to clean up and reduce pasture production. For this reason, crown management by pollarding, i.e. removing the branches at a height of $\sim 2 \mathrm{~m}$ at regular intervals, is promoted to farmers as a source of drought fodder and for size reduction [6]. Crown management also results in root management, with a reduction in the crown leading to a consequent reduction in the root system [7]. While this may be advantageous in an agroforestry system, in a silvopastoral system where the primary role of the trees is soil stabilisation any reduction in the root system can be considered disadvantageous. In addition to mitigating adverse crown effects, pollarding can provide valuable highly palatable and more readily accessible stock fodder in late summer and autumn when feed supplies are low, particularly in drought-prone regions $[8,9]$.

\section{The projected climate scenarios for New Zealand are for increased frequency of droughts and se- vere rainstorms (http://www.niwa.co.nz/our-sci- ence/climate/information-and-resources/clivar/ scenarios)}

Drought frequency has implications for fodder availability, particularly in regions currently prone to seasonal drought. While willow and poplar trees planted for soil conservation are being increasingly utilised as fodder sources in drought, management of severe storm risk on pastoral hill land relies on the presence and efficacy of the root systems of poplar and willow soil conservation trees to hold soil against the likelihood of slippage [4].

\section{The impact of pollarding on the soil stabilization role of tree willows is not known}

It is the root network of these trees that is considered to bind soil particles after the manner of reinforcing steel in concrete [10] resisting the downward movement of soil under the effects of gravity and saturation by water. Coarse roots extending laterally from the tree trunk provide the structural root network and from them other coarse and fine roots extend outwards and downwards to add stability both laterally and vertically, particularly where the bedrock is penetrated [5]. Various studies have found that fine roots (roots less than $2 \mathrm{~mm}$ in diameter) account for around 80$90 \%$ of the total root length of tree roots [11-14]. Conse- quently, any influences that potentially reduce the fine root network will reduce the effectiveness of the tree in binding soil and reducing erosion.

In this study we investigated how the immediate and medium-term effect of pollarding may alter the soil stabilizing effectiveness of tree willows by studying the root dynamics, particularly of the fine roots, of mature Salix matsudana Koidzumi $\times$ alba Linnaeus 'Tangoio' willows grown on a pastoral hill slope and following pollarding.

\section{Methods}

\section{Study location}

The study was conducted on a hill country sheep and beef farm $\left(40.1^{\circ} \mathrm{S}, 176.4^{\circ} \mathrm{E}\right)$ located approximately $10 \mathrm{~km}$ SSW of Waipukurau in the central Hawke's Bay, New Zealand, a location with a mean annual rainfall of around 785 $\mathrm{mm}$ but prone to summer drought. The farm has a well-developed conservation tree programme with substantial plantings of various ages of poplar and willow on pastoral areas. The study willow trees were located on a south-facing slope averaging $16^{\circ}$ steepness with a silt loam soil (Purimu soil: NZ Soils Database) [15] overlaying a sandstone bedrock. The slope was characterised by several old slips and the bedrock was exposed on the slip scars. While the slip scars were planted with willow trees, no trees located on slip scars were used in the study. The slope is regularly grazed by both sheep and cattle. As far as could be ascertained from the farmer, the trees in the study area were planted within a year of one another and were estimated to be 12-14 years-old.

\section{Some of the trees on the slope were pollarded (IP) for stock fodder in February 2006, while oth- er trees remained unpollarded (UP)}

Many of the IP trees were re-pollarded (RP) in February 2009 (another drought year), 4-5 days before sampling on Day 49. This management provided opportunity to assess the immediate root response to pollarding (by sampling from the RP trees), and the response at the end of a pollarding cycle (sampling the IP trees) compared with that for unpollarded trees (sampling UP trees). The diameter at breast height ( $\mathrm{DBH}$; measured at $1.4 \mathrm{~m}$ from the ground) was measured for all the trees contributing data at the beginning and at the end of the study. Pollarding involved removing all branches above $\sim 2 \mathrm{~m}$ measured from ground level. This left either short sections (100-150 mm) of major branches or just the trunk to provide the buds to produce new shoots. Trees chosen for the study were, as far as possible, of similar size, on a similar slope and greater than 8 $\mathrm{m}$ from neighbouring trees.

\section{Root sampling}

Tree roots were sampled by taking soil cores at $150 \mathrm{~mm}$ depth intervals down to $600 \mathrm{~mm}$ at two distances, $2 \mathrm{~m}$ and $3 \mathrm{~m}$ from the centre of the tree trunk. These distances, rather than distances further from the tree, were chosen to ensure a reasonable capture of roots. It was considered 
that any trend would be more apparent where the capture of roots would be greater. The $2 \mathrm{~m}$ samples were taken at $0^{\circ}$ (due North), $120^{\circ}$ and $240^{\circ}$, and the $3 \mathrm{~m}$ sample at just $240^{\circ}$. North direction was directly up the slope. Angles between $90^{\circ}$ and $270^{\circ}$ were down slope of the tree trunk and angles between $270^{\circ}$ and $90^{\circ}$ were upslope. At each sample location and at each depth, a $5 \mathrm{~mm}$ thick PVC culvert pipe with internal dimensions $190 \mathrm{~mm}$ diameter by $150 \mathrm{~mm}$ depth and with a bevelled lower lip for easier penetration was inserted into the soil and the intact soil core removed. The soil core was broken up and passed through a sieve and the live willow roots extracted and stored in a labelled plastic bag. Willow roots were golden yellow to dark brown in colour. The finest willow roots were white and generally extracted still connected to larger roots. Roots of grasses and other herbaceous species were mostly white and part of the whole plant, and were not collected. Where white root origin was uncertain (i.e. grass or willow), the root was included in the sample for identification in the laboratory. Sieved soil was replaced at the depth it was removed, although not repacked to the same bulk density. A sieved soil sample from each core was stored in a sealed plastic bag and dried the following day at $105{ }^{\circ} \mathrm{C}$ for measurement of soil moisture content. Initial root sampling of three UP and three IP trees was done in February 2009 (Day 49, late summer) just prior to re-pollarding. Subsequent samples were collected every 3 months (Days 140, 222, 320 and 416; coinciding with the end of each season) from the same three UP and IP trees together with three RP trees, with the sampling positions moved forward around the trunk by $20^{\circ}$ at each new sample date. Where large structural roots (i.e. with diameters $>20 \mathrm{~mm}$ ) were present, the sample position was adjusted to avoid including them in the sample and causing unnecessary damage to the root, tree and equipment. The final samples were taken on 10 February 2010 (Day 416).

\section{Laboratory root analyses}

In the laboratory, live willow roots were washed and sorted into diameter classes: $<1 \mathrm{~mm}, 1<2 \mathrm{~mm}, 2<5 \mathrm{~mm}, 5<$ $10 \mathrm{~mm}$ and $\geq 10 \mathrm{~mm}$ using a digital calliper. Roots not connected to larger willow roots were identified as either willow or non-willow based on their similarity in colour and tensile strength with known willow roots of similar size. Non-willow and dead willow roots were discarded. Dead willow roots were identified as black or dark brown in colour and with reduced tensile strength. The diameter classes $<1 \mathrm{~mm}$ and 1 $<2 \mathrm{~mm}$ are treated as fine (f) roots in the analyses and the larger diameter classes as coarse (c) roots. Root lengths for each group were measured with a ruler and recorded. The roots were oven-dried at $70{ }^{\circ} \mathrm{C}$ for 48 hours, and dry weights were recorded.

Table 1: Mean diameter at breast height (DBH) of the willow trees from which root samples were taken.

\begin{tabular}{|l|l|l|l|}
\hline \multicolumn{2}{|c|}{} & DBH cm & Mean annual DBH increase in cm \\
\hline Treatment & Day 1 & Day 416 & \\
\hline Unpollarded (UP) & $40.6 \pm 5.5$ & $42.8 \pm 5.3$ & $2.2 \pm 0.5$ \\
\hline Pollarded once (IP) & $36.3 \pm 3.3$ & $37.4 \pm 3.8$ & $1.4 \pm 0.6$ \\
\hline Repeat pollarded (RP) & $37.4 \pm 5.0$ & $38.1 \pm 5.1$ & $0.7 \pm 0.4$ \\
\hline
\end{tabular}

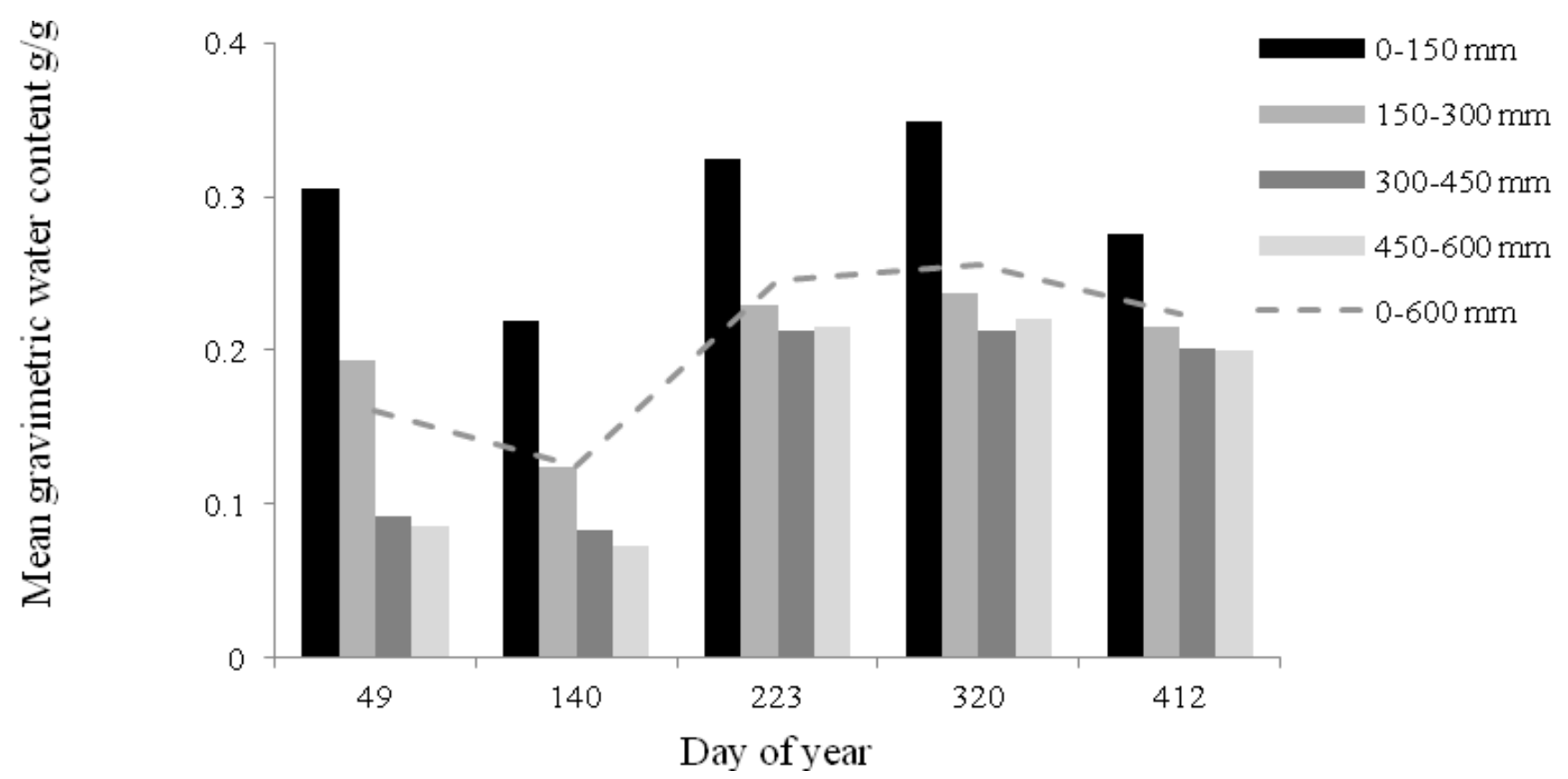

Figure 1: Mean gravimetric water content $(\mathrm{g} / \mathrm{g})$ measured at different soil depths $(\mathrm{mm})$ and at $2 \mathrm{~m}$ from the willow tree trunk for IP treatment $(\mathrm{N}=9)$ taken at 3-monthly intervals over the 13 month sampling period. 


\section{Calculations}

From the root length and dry weight data and using a core volume of $0.00425 \mathrm{~m}^{3}$ (calculated from the core dimensions given above), root length density ( $R L D$ in $\mathrm{mm}^{-3}$ ) and root mass density (RMD in $\mathrm{kgm}^{-3}$ ) for each root diameter class in each core were calculated [16]. For analyses, means were separated by treatment, position, soil depth and time. Mean RLD and RMD were higher at $2 \mathrm{~m}$ from the tree than at $3 \mathrm{~m}$, but not significantly so. However, differences with position were not usually significant because of the degree of variability of root presence around the trunk. In subsequent analyses we worked with mean RLDs and RMDs without separation for distance, and for easier comparison have elected to report \% mean RLD and \% RMD in the tables. Analysis of Variance (ANOVA) was performed on all root data in GenStat ( $14^{\text {th }}$ edition) with a significance level of $P<0.05$.

\section{Results}

\section{Tree size}

There was some unavoidable variation in the $\mathrm{DBH}$ of the trees used in the study (Table 1). Mean annual DBH increase of the RP trees $(0.7 \pm 0.4 \mathrm{~cm})$ was significantly lower $(P<0.05)$ than that of the UP trees $(2.2 \pm 0.5 \mathrm{~cm})$ (Table 1$)$.

\section{Soil water content}

The study area experienced a very dry period in the four months prior to initiating the study, and this continued through day 140 (Figure 1). Soil moisture in the second summer was much higher. Soil water decreased with depth and to a greater extent during periods of low rainfall.

Soil water content $(0-600 \mathrm{~mm})$ differed among the three treatments as the growing season progressed (from Day 223 to Day 412), being highest for the RP trees and lowest for the UP trees ( $84 \%$ of RP), with IP trees interme- diate ( $88 \%$ of RP). The soil water differences were likely contributed by higher transpiration rates, and interception of rainfall due to greater leaf area and canopy size, of UP trees compared with IP and RP trees.

\section{Root dynamics}

Root depth distribution in the unpollarded trees: Data collected on Day 49 and Day 416 are used to describe root development in the unpollarded trees (UP) during the 12-month period of the study. Root presence decreased with soil depth (Table 2). Mean root length density (RLD, $\mathrm{mm}^{-3}$ ) at 0-150 $\mathrm{mm}, 150-300 \mathrm{~mm}, 300-450 \mathrm{~mm}$ and $450-$ $600 \mathrm{~mm}$ depths was 1979, 1418, 648 and 725; 41\%, 30\%, $14 \%$ and $15 \%$ respectively, of the total RLD in the soil column 0-600 mm on Day 49. On Day 416 mean RLD in $\mathrm{mm}^{-3}$ at the same depths was 4624 (67\%), 1102 (16\%), 615 (9\%) and $519(8 \%)$, respectively. Fine roots (<2 $\mathrm{mm}$ diameter) accounted for $92 \%$ of root length on both Day 49 and Day 416. Low soil moisture during the previous 3 months (data not presented) was considered to have contributed to lower fine RLD ( $f R L D$ ) in the top $150 \mathrm{~mm}$ of soil on Day 49 compared with Day 416.

RLD decreased as the root diameter class increased for all treatments. For example, in UP trees mean RLD in $\mathrm{mm}^{-3}$ (over the soil depth 0-600 $\mathrm{mm}$ ) for the root diameter classes (in mm) $0<1,1<2,2<5,5<10$ and $\geq 10$ was 1047, 124, 77,15 and 4 respectively on Day 49 , and on Day 416 was $1232,356,94,23$ and $10 \mathrm{~mm}^{-3}$ respectively (for RP trees on Day 416 these respective values for the root diameter classes (in $\mathrm{mm}$ ) $0<1,1<2,2<5,5<10$ and $\geq 10$, were 657 , 219, 79, 13 and $9 \mathrm{~mm}^{-3}$ ).

Vertical distribution of RMD was similar to that for the RLD. Large diameter roots were found throughout the soil profile, but most roots of all diameter classes were within the 0-300 mm depth. Mean RMD within the 0-150 mm depth reduced by more than half from $2 \mathrm{~m}$ to $3 \mathrm{~m}$, but the RMD

Table 2: Mean root length density (RLD) in $\mathrm{mm}^{-3}$ for unpollarded (UP), pollarded once (IP) and repollarded (RP) willow treatments one year after repollarding, separated by root diameter class and soil depth and over the depth 0-600 mm with no separation for distance from the trunk, expressed as a \% RLD of the UP treatment. Data collected on Day 416.

\begin{tabular}{|c|c|c|c|c|c|c|c|}
\hline \multirow{3}{*}{ Treatment } & \multirow{3}{*}{ Depth (mm) } & \multicolumn{5}{|c|}{ Root Diameter class (mm) } & \multirow[b]{2}{*}{ All } \\
\hline & & $<1$ & $1<2$ & $2<5$ & $5<10$ & $\geq 10$ & \\
\hline & & \multicolumn{6}{|c|}{ Root Length Density as a \% of the unpollarded treatment } \\
\hline \multirow[t]{5}{*}{ IP } & $0-150$ & 102 & 90 & 72 & 102 & 169 & 99 \\
\hline & $150-300$ & 129 & 73 & 92 & 222 & 141 & 112 \\
\hline & $300-450$ & 102 & 73 & $186\left(^{*}\right)$ & 62 & 37 & 96 \\
\hline & $450-600$ & 94 & 61 & 111 & 119 & 158 & 84 \\
\hline & $0-600$ & 106 & 81 & 88 & 109 & 118 & 100 \\
\hline \multirow[t]{5}{*}{$\mathrm{RP}$} & $0-150$ & $37^{*}$ & 56 & 72 & 68 & 97 & $42^{*}$ \\
\hline & $150-300$ & 101 & 66 & 99 & 77 & 228 & 91 \\
\hline & $300-450$ & 84 & 84 & 103 & 38 & 49 & 83 \\
\hline & $450-600$ & 92 & 57 & 114 & 0 & 89 & 80 \\
\hline & $0-600$ & $53^{*}$ & 62 & 83 & 59 & 93 & $57^{*}$ \\
\hline
\end{tabular}

Significant $(P<0.05)$ differences from the UP value marked with an asterisk; near-significant differences marked with a $\left({ }^{*}\right)$. 

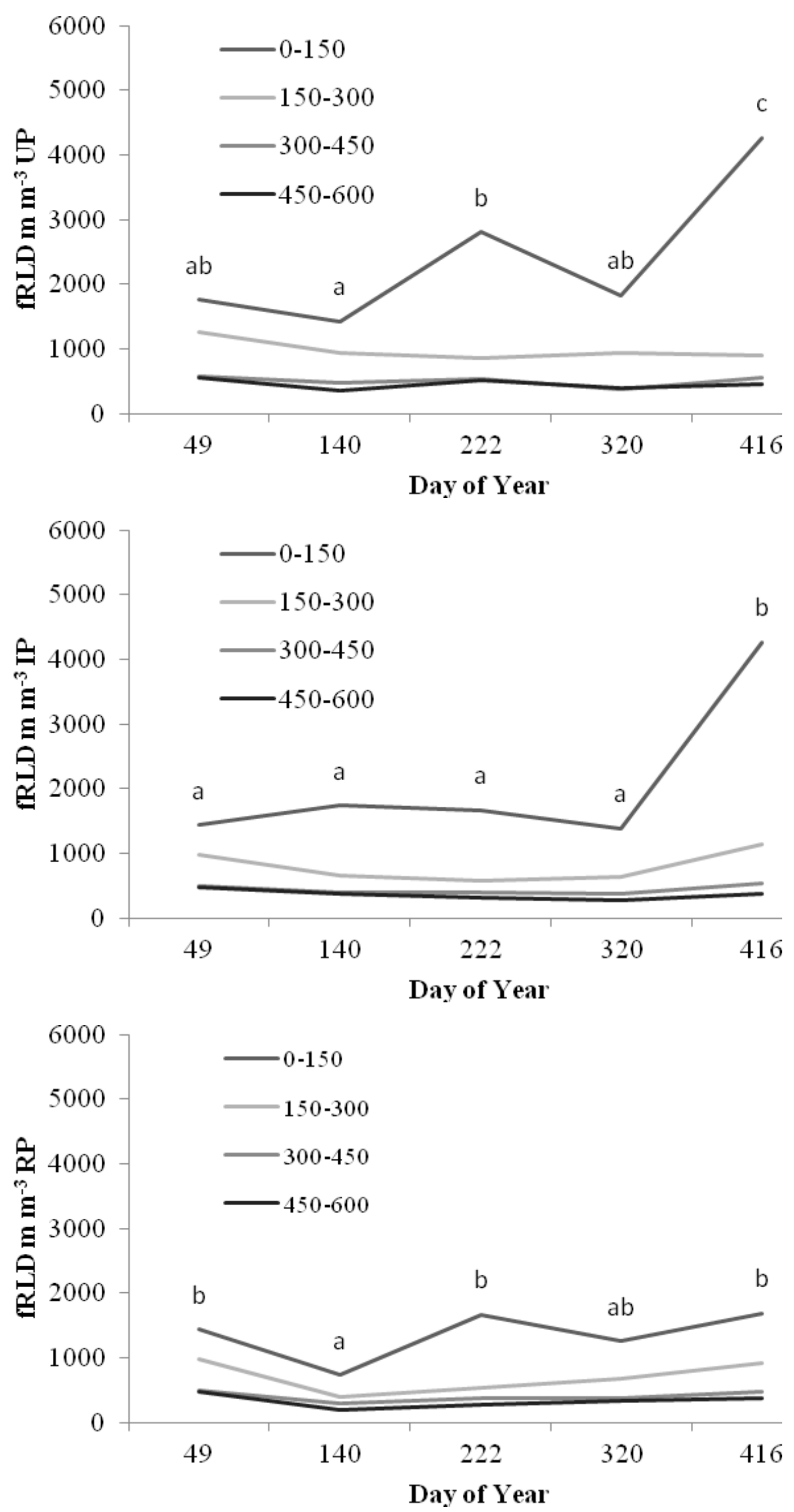

Figure 2: Annual mean changes in fine root length density (fRLD) in $\mathrm{mm}^{-3}$ for the unpollarded (top), once pollarded (middle) and repeat pollarded (bottom) willow trees (includes samples from $2 \mathrm{~m}$ and $3 \mathrm{~m} ; \mathrm{N}=12$ for each treatment and sample time). Within a graph, points on the $150 \mathrm{~mm}$ series with a common letter are not significantly different based on least significant difference. 


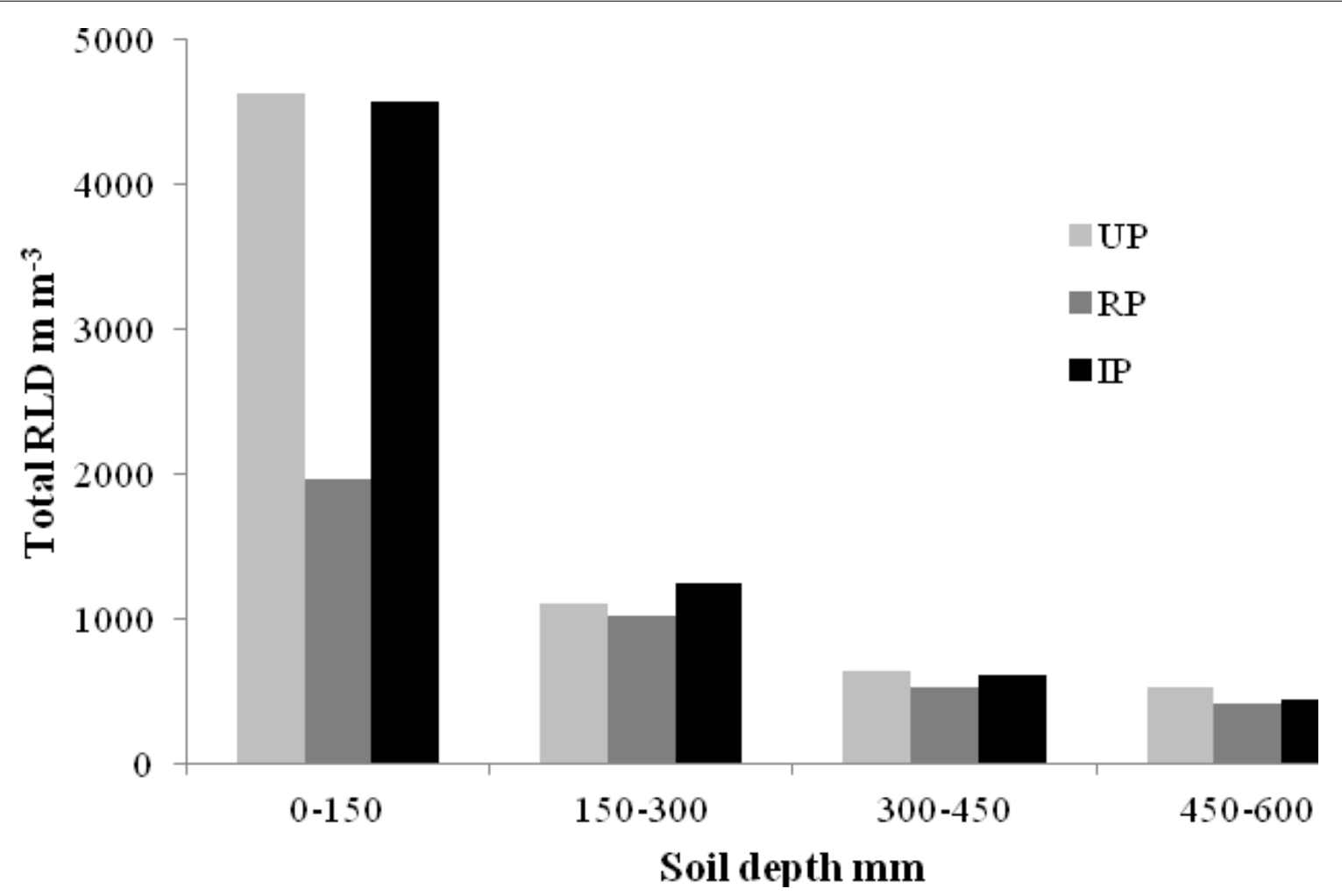

Figure 3: Total mean willow root length density varying with soil depth for the three treatments 1 year after repollarding (Day 416 data; $N=12$ for each treatment) (unpollarded (UP); pollarded once (IP); repollarded (RP)).

Table 3: Mean root mass density (RMD, $\mathrm{kg} \mathrm{m}^{-3}$ ) for the two willow treatments (pollarded once (IP) and repollarded (RP)) 1 year following repollarding for the different depths and diameter classes, separated by root diameter class and soil depth, and expressed as a \% of the unpollarded treatment.

\begin{tabular}{|c|c|c|c|c|c|c|c|}
\hline \multirow{3}{*}{ Treatment } & \multirow{3}{*}{ Depth mm } & \multicolumn{6}{|c|}{ Root diameter class mm } \\
\hline & & $<1$ & $1<2$ & $2<5$ & $5<10$ & $>10$ & All \\
\hline & & \multicolumn{6}{|c|}{ Root Mass Density as a \% of the unpollarded treatment } \\
\hline \multirow{5}{*}{ IP } & $0-150$ & 90 & 93 & $65^{*}$ & 95 & 134 & 105 \\
\hline & $150-300$ & 138 & 107 & 185 & $288\left({ }^{*}\right)$ & 166 & 181 \\
\hline & $300-450$ & $132\left({ }^{*}\right)$ & 83 & 128 & 75 & 28 & 45 \\
\hline & $450-600$ & 91 & 89 & 28 & 116 & 234 & 157 \\
\hline & $0-600$ & 99 & 94 & 82 & 107 & 114 & 105 \\
\hline \multirow{5}{*}{ RP } & $0-150$ & $33^{*}$ & $63\left(^{*}\right)$ & $65^{*}$ & 47 & 184 & 105 \\
\hline & $150-300$ & 73 & 93 & 105 & 61 & $612\left(^{*}\right)$ & 216 \\
\hline & $300-450$ & $69\left(^{*}\right)$ & 81 & 114 & 27 & 106 & 98 \\
\hline & $450-600$ & 66 & 67 & 54 & 0 & 13 & 19 \\
\hline & $0-600$ & $42^{*}$ & 70 & 73 & 40 & 161 & 103 \\
\hline
\end{tabular}

Significant $(P<0.05)$ differences from the UP value marked with an asterisk; near-significant differences marked with a $\left(^{*}\right)$.

from the $150-600 \mathrm{~mm}$ depth varied little between the two distances.

Seasonal changes in tree willow root system under the three treatments: Fine RLD (Figure 2) declined from Day 49 to a low point on Day 140 (end of autumn), increased through the winter to Day 222, with a decline in spring to Day 320 followed by a steep increase through the summer.

Response of the tree willow root system immediately after pollarding: Pollarding led to an immediate reduction in RLD and RMD. Root parameters of the RP and IP trees were treated as the same on Day 49. From Day 49 to Day 140, RP RLD declined by $48 \%$, whereas IP RLD declined by $4 \%$. On Day 140, coarse root length density (cRLD) of RP trees was $74 \%$ of cRLD of IP trees, whereas fRLD of RP trees was only $52 \%$ of fRLD of IP trees. In the top $300 \mathrm{~mm}$ of soil 90 days after repollarding, fRLD of RP trees had reduced from $71 \%$ to $63 \%$ of total RLD. For IP trees on Day 140 , fRLD 
accounted for $95 \%$ of RLD, whereas for RP trees fRLD was only $80 \%$ of total RLD, showing that the greater reduction of RLD was in fine roots. However, RP CRLD was $74 \%$ of IP CRLD 90 days following pollarding, with recruitment to root diameter classes $2<5 \mathrm{~mm}$ and $5<10 \mathrm{~mm}$ being lower (Table 3). One year following pollarding, the differences in RLD continued to be most apparent in the top $300 \mathrm{~mm}$ of soil (Tables 2 and Table 3 ).

Response of the tree willow root system one year after pollarding: One year following pollarding, mean RP treatment RLD for soil depth $0-600 \mathrm{~mm}$ was significantly lower (57\%; $P<0.01$ ) than that of UP and IP treatments (Table 2, Figure 3). RP fRLD was significantly lower at 0-150 $\mathrm{mm}$ and 150-300 $\mathrm{mm}$ soil depths $(P<0.05)$ than fRLD in IP and UP treatments (Table 3 and Table 4 ) but not at depths below $300 \mathrm{~mm}$.

Differences in IP and UP RLD were small, suggesting that 4 years after pollarding there was no remaining significant reduction of RLD within $3 \mathrm{~m}$ of the trunk. The greatest reduction of RLD in RP was in the fine roots, which represent the majority of RLD.

Response of the tree willow root system 3 years after pollarding: Mean RMD and RLD were lower, although not significantly, for the trees that had been pollarded 3 years previously (IP) than for the unpollarded trees (Tables 3 and Table 4). The greatest mean reduction was for fine roots with diameter $<1 \mathrm{~mm}$. There was considerable variability in root distribution around the trees.

\section{Discussion}

Typically fine roots are defined as those roots $<2 \mathrm{~mm}$ in diameter $[17,18]$. Fine root size classes include many roots which have relatively long life expectancies: Roots that serve primarily transport and storage functions [12]. In this study fine roots of diameter $1<2 \mathrm{~mm}$ were usually brown in colour and lignified and were considered to be non-absorbing and long-lived. However, there were roots in this diameter class that were white in colour, i.e. newly formed roots. Fine roots are both morphologically and physiologically responsive to changes in water and nutrient availability [19]. Of the roots in diameter class $<1 \mathrm{~mm}$ many were also brown in colour and lignified, with the diameters being smaller possibly a consequence of pollarding though this could not be determined. Pollarding was reported to depress short term fine root production and growth reduce the glucose concentrations and increase the proportion of dead roots in Acacia saligna and Amorpha fruticosa $[17,20]$, possibly because of resources being redirected to produce new shoots and leaves.

Little information has been published on fine root growth responses to tree pollarding, though studies of coppiced tree species contribute useful insights. Fine roots contribute little to root mass, so changes in fine root mass are not easily recognised unless they are analysed separately from coarse roots. Coppiced beech stands had lower fine-root production and turnover than stands converted from coppice to high forest [21], as found in this study of pollarded willow. Both fine-root production and turnover rate of beech were sensitive to management practices. Pollarding crape myrtle (Lagerstroemia indica) altered flowering times and increased height growth [22]. New root production was lower for heavily pruned than for lightly pruned walnut trees, with differences being less pronounced in the following season [23]. For Erythrina poeppigiana the effect of pruning all branches, compared with retaining one branch, on mean fine root length was a reduction of $40 \%$ for 2 -year-old-trees, and $49 \%$ for 8 -yearold-trees [24]. Likewise, root pruning suppressed above ground growth in potted plants of the warm temperate conifer Cunninghamia lanceolate particularly under soil water stress [25]. Salix matsudana willows responded quickly to root pruning by growing below the depth of pruning [26] suggesting that they readily adapt to new situations that affect growth. Shoot pruning and mulching recycle tree biomass and reduce the immobilization of nutrients in the trees. Pruning also reduces tree transpiration and thereby competition with pasture and crops for soil water. However, drastic pruning, with removal of the entire

Table 4: Repollarded (RP) and pollarded once (IP) root length density (RLD, $\mathrm{mm}^{-3}$ ) and root mass density (RMD, $\mathrm{kg} \mathrm{m}^{-3}$ ) as measured on Day 49 (i.e, 49 days after RP trees were repollarded).

\begin{tabular}{|c|c|c|c|c|c|}
\hline \multicolumn{6}{|c|}{ Root Length Density $\mathrm{mm}^{-3}$} \\
\hline \multirow[t]{2}{*}{ Treatment } & \multicolumn{2}{|c|}{ Fine roots } & \multirow{2}{*}{$\begin{array}{l}\text { Total fine roots } \\
<2 \mathrm{~mm}\end{array}$} & \multirow{2}{*}{$\begin{array}{l}\text { Coarse roots } \\
2<10 \mathrm{~mm}\end{array}$} & \multirow{2}{*}{\begin{tabular}{|l|} 
Total all roots \\
$<1$ to $>10 \mathrm{~mm}$
\end{tabular}} \\
\hline & $<1 \mathrm{~mm}$ & $1<2 \mathrm{~mm}$ & & & \\
\hline UP & 1047 & 124 & 1171 & 92 & 1268 \\
\hline IP & 781 & 104 & 885 & 79 & 975 \\
\hline$I P / U P$ & 0.75 & 0.79 & 0.76 & 0.97 & 0.77 \\
\hline \multicolumn{6}{|c|}{ Root Mass Density gm ${ }^{-3}$} \\
\hline \multirow[t]{2}{*}{ Treatment } & \multicolumn{2}{|c|}{ Fine roots } & Total fine roots & Coarse roots & Total all roots \\
\hline & $<1 \mathrm{~mm}$ & $1<2 \mathrm{~mm}$ & $<2 \mathrm{~mm}$ & $2<10 \mathrm{~mm}$ & $<1$ to $>10 \mathrm{~mm}$ \\
\hline UP & 174 & 85 & 259 & 489 & 956 \\
\hline IP & 108 & 79 & 187 & 409 & 1754 \\
\hline$I P / U P$ & 0.62 & 0.89 & 0.70 & 2.61 & 2.02 \\
\hline
\end{tabular}

Significant $(P<0.05)$ differences from the UP value are marked with an asterisk. 
leaf biomass, may have other unfavourable effects. It has been observed to cause nodule death and strongly reduce nodule activity for E. poeppigiana in Costa Rica [27] and for Leucaena diversifolia in Burundi $[28,29]$. While nodule associations are not found in tree willows, disruption to endophytic and mycorrhizal associations are likely to be short-lived in this species since it has the ability to quickly produce new photosynthetic shoots following pollarding. Certainly no long-term tree health deterioration has been reported for willows following coppicing or severe pruning.

Plant roots preferentially grow through structural weaknesses within the soil and can frequently be observed within existing macropores $[29,30]$. The additional soil macropores and lower bulk density following reduction in fRLD may promote root extension of herbaceous pastoral species and enhancement of pasture production [31] though this was not assessed in the present study.

Pollarding of mature willow trees led to an immediate reduction in $f R L D$ within $3 \mathrm{~m}$ of the trunk, primarily in the upper soil layers, where the majority of fine roots were found. Reduction in fine root presence in the top $150 \mathrm{~mm}$ of soil following pollarding is likely a response to reduced photosynthate and competition with pasture for soil moisture. If the reduction in fRLD following pollarding as observed close to the trunk is experienced throughout the root network, recovery of fRLD of pollarded willows to that of unpollarded willows will take between 3 and 4 years, as suggested by fRLD for IP trees. While fine root length density is not directly proportional to root function when comparing different species [32] it is reasonable to conclude that for trees which are clonal (as in this study), trees with high fine root length densities are likely to be more effective at taking up water and binding soil than trees with lower root length density. Nevertheless, trees may have a high concentration of roots in the topsoil and still have some very deep roots which may reduce their susceptibility to drought [7]. The less severe reduction in fRLD deeper in the soil profile may be a real effect rather than an aberration of low fRLD at depth. To retain soil binding effectiveness of the fine roots, regular pollarding of tree willow grown under these environmental conditions should not occur more frequently than every 3 to 4 years, the time difference depending on available soil moisture during the growing season. If other needs allow it, no more than between a quarter and a third of trees protecting a slope from soil erosion should be pollarded in any one year, and the pollarded trees should be distributed across the slope. In this way, the impact of RLD loss resulting from pollarding can be minimised. The reduction in root length density induced by regular pollarding could also be compensated by planting trees closer together. There was no significant reduction in coarse root parameters identified in this study. However, poplars had significantly reduced coarse root biomass four years after pollarding [6]. Similar impacts on coarse roots to those found for pollarded poplar are expected to be demonstrable in pollarded tree willows over a longer time period.

This study was carried out with mature trees with diam- eter in the range $32-45 \mathrm{~cm}$. It is expected that the effect of pollarding on trees with a smaller trunk diameter would be more severe, since coarse root development is not well advance in juvenile stages, the nutrient resources available for recovery of RLD and RMD are much less and the root network will likely not be as uniformly distributed at a younger age $[6,13,29,33-35]$. Further studies are required to determine for smaller trees the rate of root recovery following pollarding and to provide advice to landowners on when to initiate pollarding as a management option. The development of a tool that relates above-ground recovery following pollarding to root recovery would also be useful in assisting decision making on pollarding frequency.

\section{Conclusions}

Pollarding of mature willow trees leads to a significant reduction in fine root length density compared with unpollarded trees, notably in the upper $300 \mathrm{~mm}$ soil depth. Recovery of fine roots to a density comparable with unpollarded trees is considered to take 3-4 years. Where willows are also planted for soil stabilisation and erosion control pollarding reduces soil binding and dewatering of the slope. Consequently we recommend that pollarding not be repeated at intervals less than 3-4 years, and then not for all trees on the slope simultaneously.

\section{Acknowledgements}

Funding for this study was provided by New Zealand Ministry for Primary Industries (Contract 23273) and various Regional Councils. We thank the Ennor family for access to their farm and for pollarding their trees. We thank Roberta Gentile and Rocky Renquist for reviews of previous drafts of this manuscript.

\section{References}

1. Mclvor IR, Hedderley DI, Hurst SE, et al. (2011) Survival and growth to age 8 of four Populus maximowiczii $\times$ P. nigra clones in field trials on pastoral hill slopes in six climatic zones of New Zealand. New Zealand Journal of Forestry Science 41: 151-163.

2. Wilkinson AG (1999) Poplars and willows for soil erosion control in New Zealand. Biomass and Bioenergy 16: 263-274.

3. Lambert MG, Trustrum NA, Costall DA (1984) Effect of soil slip erosion on seasonally dry Wairarapa hill pastures. New Zealand Journal of Agricultural Research 27: 57-64.

4. Douglas GB, Mclvor IR, Manderson AK, et al. (2013) Reducing shallow landslide occurrence in pastoral hill country using widespaced trees. Land Degradation \& Development 24: 103-114.

5. Gray DH, Sotir RB (1996) Biotechnical and soil engineering slope stabilization: A practical guide for erosion control. Wiley, New York.

6. Mclvor I, Douglas G, van den Dijssel C, et al. (2019) Pollarding wide-spaced poplar trees on pastoral hillslopes alters root development. Agroforestry Systems 93: 2227-2241.

7. Schroth $G$ (1998) A review of belowground interactions in agroforestry, focussing on mechanisms and management options. Agroforestry Systems 43: 5-34.

8. McWilliam EL, Barry TN, Lopez-Villalobos N, et al. (2005) Effects of willow (Salix) supplementation for 31 and $63 \mathrm{~d}$ on the repro- 
ductive performance of ewes grazing low quality drought pasture during mating. Animal Feed Science and Technology 119: 87-106.

9. Pitta DW, Barry TN, Lopez-Villalobos N, et al. (2009) Effect of willow supplementation upon plasma amino acid concentration in ewes grazing drought pastures of low nutritive value. Animal Feed Science and Technology 148: 183-191.

10. Gray DH (1995) Influence of vegetation on the stability of slopes. Vegetation and Slopes: Stabilisation, protection and ecology. 2-25.

11. Coleman MD, Dickson RE, Isebrands JG (2000) Contrasting fineroot production, survival and soil $\mathrm{CO} 2$ efflux in pine and poplar plantations. Plant and Soil 225: 129-139.

12. Pregitzer KS, DeForest JL, Burton AJ, et al. (2002) Fine root architecture of nine North American trees. Ecological Monographs 72: 293-309.

13. Mclvor IR, Douglas GB, Hurst SE, et al. (2008) Structural root growth of young Veronese poplars on erodible slopes in the southern North Island, New Zealand. Agroforestry Systems 72: 75-86.

14. Phillips CJ, Marden M, Lambie S, et al. (2013) Observations of below-ground characteristics of young redwood trees (Sequoia sempervirens) from two sites in New Zealand - implications for erosion control. Plant and Soil 363: 33-48.

15. Hewitt AE (2010) New Zealand soil classification. (3 $3^{\text {rd }}$ edn), Landcare Research Science Series No. 1, Lincoln, Manaaki Whenua Press.

16. Jerbi A, Guidi NW, Fluet R, et al. (2015) Willow root development and morphology changes under different irrigation and fertilization regimes in a vegetation filter. BioEnergy Research 8: 775-787.

17. Peter I, Lehmann J (2000) Pruning effects on root distribution and nutrient dynamics in an acacia hedgerow planting in northern Kenya. Agroforestry Systems 50: 59-75.

18. Plante PM, Rivest D, Vezina A, et al. (2014) Root distribution of different mature tree species growing on contrasting textured soils in temperate windbreaks. Plant and Soil 380: 429-439.

19. Pregitzer KS (2002) Fine roots of trees - a new perspective. New Phytologist 154: 267-270.

20. Carrillo Y, Jordan CF, Jacobsen KL, et al. (2011) Shoot pruning of a hedgerow perennial legume alters the availability and temporal dynamics of root-derived nitrogen in a subtropical setting. Plant and Soil 345: 59-68.

21. Montagnoli A, Terzaghi M, Di lorio A, et al. (2012) Fine-root morphological and growth traits in a Turkey-oak stand in relation to seasonal changes in soil moisture in the Southern Apennines, Italy. Ecological Research 27: 1015-1025.
22. Gilman EF, Knox GW, Gomez-Zlatar P (2008) Pruning method affects flowering and sprouting on crapemyrtle. J Environ Hort 26: 164-170.

23. Contador ML, Comas LH, Metcalf SG, et al. (2015) Root growth dynamics linked to above-ground growth in walnut (Juglans regia). Ann Bot 116: 49-60.

24. Chesney $P$ (2008) Nitrogen and fine root length dynamics in a tropical agroforestry system with periodically pruned Erythrina poeppigiana. Agroforestry Systems 72: 149-159.

25. Dong TF, Duan BL, Zhang S, et al. (2016) Growth, biomass allocation and photosynthetic responses are related to intensity of root severance and soil moisture conditions in the plantation tree Cunninghamia lanceolata. Tree Physiol 36: 807-817.

26. Hughes KA, Edwards WRN, Snowball AM (1994) Control of willow-tree shelter root systems in kiwifruit orchards by root pruning. New Zealand Journal of Crop and Horticultural Science 22: 103-110.

27. Nygren $P$, Campos A (1995) Effect of foliage pruning on fine root biomass of Erythrina-Poeppigiana (Fabaceae). Ecophysiology of Tropical Intercropping 295-302.

28. Snoeck D (1996) Beneficial effects of Leucaena Rhizobium association on coffee in Burundi. Plantations, Recherche, Developpement 3: 408-417.

29. Schroth G, Lehmann J, Rodrigues MRL, et al. (2001) Plant-soil interactions in multistrata agroforestry in the humid tropics. Agroforestry Systems 53: 85-102.

30. Vannoordwijk M, Widianto, Heinen M, et al. (1991) Old tree root channels in acid soils in the humid tropics: Important for crop root penetration, water infiltration and nitrogen management. Plant and Soil 134: 37-44.

31. Miller DE (1986) Root systems in relation to stress tolerance. HortScience 21: 963-970.

32. Caldwell M (1994) Exploiting nutrients in fertile soil microsites. In: Caldwell MM, Pearcy RW, Exploitation of environmental heterogeneity by plants. Academic Press, San Diego, 325-347.

33. Lang $P$, Jeschke $M$, Wommelsdorf $T$, et al. (2015) Wood harvest by pollarding exerts long-term effects on Populus euphratica stands in riparian forests at the Tarim River, NW China. Forest Ecology and Management 353: 87-96.

34. Pham HT, Miyagawa S, Kosaka Y (2015) Distribution patterns of trees in paddy field landscapes in relation to agro-ecological settings in northeast Thailand. Agriculture Ecosystems \& Environment 202: 42-47.

35. Milliken W, Gasson P, Pareyn F, et al. (2018) Impact of management regime and frequency on the survival and productivity of four native tree species used for fuelwood and charcoal in the caatinga of northeast Brazil. Biomass and Bioenergy 116: 18-25.

DOI: $10.36959 / 742 / 221$

Copyright: (C) 2020 Mclvor IR, et al. This is an open-access article distributed under the terms of the Creative Commons Attribution License, which permits unrestricted use, distribution, and reproduction in any medium, provided the original author and source are credited. 